\title{
Comparison of the effects of sugammadex and neostigmine on hospital stay in robot- assisted laparoscopic prostatectomy: a retrospective study
}

\author{
Byung-Hun Min ${ }^{1 \dagger}$, Tak Kyu Oh ${ }^{1,2+}$, In-Ae Song $^{1,2^{*}}$ (i) and Young-Tae Jeon ${ }^{1,3}$
}

\begin{abstract}
Background: Sugammadex reduces postoperative complications. We sought to determine whether it could reduce the length of hospital stay, post-anesthetic recovery time, unplanned readmission, and charges for patients who underwent robot-assisted laparoscopic prostatectomy (RALP) when compared to neostigmine.

Methods: This was a retrospective observational study of patients who underwent RALP between July 2012 and July 2017, in whom rocuronium was used as a neuromuscular blocker. The primary outcome was the length of hospital stay after surgery in patients who underwent reversal with sugammadex when compared to those who underwent reversal with neostigmine. The secondary outcomes were post-anesthetic recovery time, hospital charges, and unplanned readmission within 30 days after RALP.

Results: In total, 1430 patients were enrolled. Using a generalized linear model in a propensity score-matched cohort, sugammadex use was associated with a $6 \%$ decrease in the length of hospital stay (mean: sugammadex 7.7 days vs. neostigmine 8.2 days; odds ratio [OR] 0.94, 95\% confidence interval [CI] [0.89, 0.98], $P=0.008$ ) and an 8\% decrease in post-anesthetic recovery time (mean: sugammadex 36.7 min vs. neostigmine $40.2 \mathrm{~min} ; \mathrm{OR} \mathrm{0.92,95 \%} \mathrm{Cl}$ $[0.90,0.94], P<0.001)$ as compared to neostigmine use; however, it did not reduce the 30-day unplanned readmission rate $(P=0.288)$. The anesthesia charges were higher in the sugammadex group than in the neostigmine group $(P<0.001)$; however, there were no significant differences between the groups in terms of postoperative net charges $(P=0.061)$ and total charges $(P=0.100)$.

Conclusions: Compared to the reversal of rocuronium effects with neostigmine, reversal with sugammadex after RALP was associated with a shorter hospital stay and post-anesthetic recovery time, and was not associated with 30-day unplanned readmission rates and net charges.
\end{abstract}

Keywords: Hospital length of stay, Neuromuscular blocking agents, Reversal agents, Rocuronium, Sugammadex

\footnotetext{
* Correspondence: songoficu@outlook.kr

${ }^{\dagger}$ Byung-Hun Min and Tak Kyu Oh contributed equally to this work.

'Department of Anesthesiology and Pain Medicine, Seoul National University

Bundang Hospital, Gumi-ro 173 Beon-gil, Bundang-gu, Seongnam-si,

Gyeonggi-do, Republic of Korea

${ }^{2}$ Interdepartment of Critical Care Medicine, Seoul National University

Bundang Hospital, 166, Gumi-ro 173 Beon-gil, Bundang-gu, Seongnam-si,

Gyeonggi-do 463-707, Republic of Korea

Full list of author information is available at the end of the article
}

(C) The Author(s). 2020 Open Access This article is licensed under a Creative Commons Attribution 4.0 International License, which permits use, sharing, adaptation, distribution and reproduction in any medium or format, as long as you give appropriate credit to the original author(s) and the source, provide a link to the Creative Commons licence, and indicate if changes were made. The images or other third party material in this article are included in the article's Creative Commons licence, unless indicated otherwise in a credit line to the material. If material is not included in the article's Creative Commons licence and your intended use is not permitted by statutory regulation or exceeds the permitted use, you will need to obtain permission directly from the copyright holder. To view a copy of this licence, visit http://creativecommons.org/licenses/by/4.0/. The Creative Commons Public Domain Dedication waiver (http://creativecommons.org/publicdomain/zero/1.0/) applies to the data made available in this article, unless otherwise stated in a credit line to the data. 


\section{Background}

Sugammadex rapidly reverses the effects of neuromuscular blockade (NMB) from agents such as rocuronium or vecuronium. It is much more expensive than classical acetyl-cholinesterase inhibitors for the reversal of NMB (e.g., neostigmine). However, it can rapidly and definitively eliminate the effect of NMB, without causing side-effects due to muscarinic receptor activation [1]. Sugammadex could better reduce the hospital length of stay (LOS), and accelerate the postoperative discharge from the post-anesthesia care unit (PACU), compared to neostigmine in patients who underwent general abdominal surgery; however, it increased NMB and NMB reversal-related costs [2, $3]$. Few studies have assessed the cost-effectiveness of sugammadex, and their results were controversial because healthcare systems differ markedly among countries [4]. For example, in a retrospective study in Italy, sugammadex eliminated postoperative residual curarization and saved costs related to residual NMB management [5]. In contrast, in an evidence-based review, there was little evidence of economic advantage for sugammadex use [4] . On the other hand, a previous study revealed that sugammadex reduced hospital LOS, 30-day unplanned readmission, and the hospital charge for patients undergoing major abdominal surgeries [6].

However, there has been no report on the effects of using sugammadex for robot-assisted laparoscopic prostatectomy (RALP), a costly but promising surgery that has a relatively lower complication risk and faster recovery than open retropubic surgery; however, it involves an operation lasting several hours in a very steep Trendelenburg position [7]. In a prolonged Trendelenburg position, the mean airway pressure increases following reduced vital capacity and forced expiratory volume 1 at 5 days postoperatively [8]. Additionally, increased abdominal pressure causes pulmonary complications, such as aspiration or atelectasis [9]. Therefore, a rapid and proper reversal of NMB in RALP might reduce the hospital stay, post-anesthetic recovery time, readmission rate and charge by facilitating early mobilization and breathing exercises. We sought to determine whether sugammadex could reduce postoperative hospital LOS, post-anesthetic recovery time, hospital charges, and 30-day unplanned readmission in patients undergoing RALP.

\section{Methods}

\section{Ethics approval and consent to participate}

This study was approved by the Institutional Review Board (B-1901/514-115) of Seoul National University Bundang Hospital, which waived the requirement for obtaining informed patient consent.

\section{Study design, participants, and data collection}

In this retrospective cohort study, all patient data were collected from electronic medical records. A medical informatics team extracted the medical records based on the patient selection criteria. Patients aged >19 years who underwent elective RALP under general anesthesia between July 1, 2012, and July 31, 2017, were reviewed. We included patients who were administered only rocuronium. Patients who underwent combined surgeries (e.g., prostatectomy combined with nephrectomy), who were admitted to the intensive care unit without NMB reversal, or who had incomplete records were excluded.

Patients demographic characteristics (age, height, weight, body mass index), perioperative conditions (Charlson Comorbidity Index, American Society of Anesthesiologists physical status classification [ASA class], hospital LOS, 30-day unplanned readmission), and anesthesia and operative factors (types of sedatives, inhalational anesthetics, dose of remifentanil, and types and dose of $\mathrm{NMB}$ and reversal agents, duration of anesthesia, recovery time from anesthesia in PACU, estimated blood loss, and surgical proficiency) were reviewed.

\section{Anesthesia for RALP}

RALP was performed under general anesthesia using inhalation anesthetics such as sevoflurane or desflurane or continuous propofol infusion with continuous intravenous remifentanil infusion. Propofol $\left(1.5 \mathrm{mg} \mathrm{kg}^{-1}\right)$ was used to induce anesthesia when using inhalational anesthetics. Intravenous injection of a rocuronium bolus was used to initiate and maintain muscle relaxation under train-of-four (TOF) monitoring using a nerve stimulator. Neostigmine $\left(0.02-0.05 \mathrm{mg} \mathrm{kg}^{-1}\right)$ or sugammadex $\left(2 \mathrm{mg} \mathrm{kg}^{-1}\right)$ was used to reverse rocuronium. In all patients receiving neostigmine, glycopyrrolate was coadministered to prevent cholinergic complications.

\section{Clinical outcomes}

The primary outcome was the difference in postoperative hospital LOS. Secondary outcomes were the postanesthetic recovery time in the PACU, hospital charges and unplanned readmission within 30 days. The net hospital charge was defined as the total charge minus the charge of surgery and anesthesia. In South Korea, the national healthcare insurance covers two-thirds of the healthcare charge, and its coverage standard is updated regularly [10]. Data on unplanned hospital readmissions within 30 days of discharge after RALP were collected from electronic medical records. Patients who required readmissions for further evaluation and treatment of other underlying diseases were excluded. 


\section{Statistical analysis}

Categorical variables are presented as medians (25th/ 75th percentile) and numbers (\%), whereas continuous variables are presented as mean (standard deviation) values. To adjust for confounding factors, we used the propensity score matching method without replacement, to balance covariates between groups. Age (> 65 years), Body mass index, Charlson Comorbidity Index score, ASA score (Classes 1, 2, and $\geq 3$ ), intraoperative rocuronium, and remifentanil dosage, and total intravenous anesthesia (TIVA), duration of anesthesia (h), estimated blood loss (L), surgical proficiency (surgeons with experience in more than 200 cases [11]), and distance between home and hospital were matched as covariates in a 1:1 ratio between the groups, with a 0.3 caliper, by the nearest neighbor method. Sufficient covariate balance between the groups was determined by an absolute standardized difference $\leq 0.1$. The MatchIt package of the $\mathrm{R}$ program (version 3.4.4; www.r-project.org) was used for propensity score-matching; the analysis was performed with SPSS software (IBM SPSS Statistics ver. 24; IBM Corp., Armonk, NY, USA).

After confirming balance in the matched cohort, generalized linear models with a logarithmic link function, with a Poisson distribution, were used to analyze correlations of NMB reversal agent with post-surgical hospital LOS and the post-anesthetic recovery time. Generalized linear models with a logarithmic link function with the gamma distribution were used to analyze the correlation between hospital charge and reversal agent. The association between the 30-day unplanned readmission rate and reversal agent was analyzed using binary logistic regression analysis.

$P$-values $<0.05$ were considered statistically significant.

\section{Results}

This study eventually included 1430 patients. In total, 1475 patients underwent elective RALP from July 1, 2012, to July 31, 2017; of these, 45 were excluded because rocuronium was not used intraoperatively $(n=38)$ or medical records were incomplete $(n=7)$. Sugammadex was used in 924 (64.6\%), and neostigmine was used in 506 (35.4\%) patients in this study (Fig. 1).

Patient demographics and clinical outcomes are described in Table 1. The mean age was 66.3 years; all patients were male, and 1329 (93\%) patients were ASA class 1 or 2. During anesthesia, $970 \mathrm{mcg}$ of remifentanil and $81 \mathrm{mg}$ of rocuronium were used on average for a mean of $4.0 \mathrm{~h}$. The mean postoperative hospital LOS was 7.8 days. Twenty-nine patients were unexpectedly readmitted to the hospital within 30 days postoperatively. The mean hospital charge was $\$ 2918$.

Unplanned surgery-related readmission within 30 days occurred in 18 patients (1.3\%) (Table 1). The most common causes of such readmissions were voiding difficulty requiring Foley insertion (10/18, 56\%), intrapelvic fluid collection requiring percutaneous catheter drainage $(4 / 18,22 \%)$, and ileus $(2 / 18,11 \%)$.

Table 2 shows the pre-propensity score matching (sugammadex group: 924; neostigmine group: 506) and post-propensity score matching (sugammadex group: 444; neostigmine group: 444) covariate comparisons. After propensity score matching, all covariates were well-balanced (absolute standardized difference $\leq 0.1$ ). The propensity score distribution became similar between groups after propensity score matching.

On a Poisson generalized linear model with a logarithmic link function using the propensity score-matched cohort, sugammadex use (vs. neostigmine) was associated with $6 \%$ decrease in hospital LOS (OR 0.94, 95\% CI $[0.89,0.98], P=0.008)$ and $8 \%$ decrease in postanesthetic recovery time (OR $0.92,95 \%$ CI [0.90, 0.94], $P<0.001)$; however, this did not reduce the 30-day unplanned readmission rate (Table $3 ; P=0.288$ ).

On a gamma generalized linear model with a logarithmic link function with the propensity score-matched cohort, the anesthesia charge was increased (OR 1.07, $95 \%$ CI $[1.04,1.10], P<0.001)$ in patients who received sugammadex, compared to those who received neostigmine. However, there were no significant differences between the groups as regards postoperative net charge (OR 1.04, 95\% CI $[1.00,1.09], P=0.061$ ) and total charge (OR 0.98, 95\% CI $[0.96,1.00], P=0.100$; Table 4 ).

\section{Discussion}

In this study, the reversal of NMB using sugammadex in RALP was shown to reduce the hospital LOS by $6 \%$ and decrease the post-anesthetic recovery time by $8 \%$, compared to neostigmine; however, there was no impact on unplanned readmission within 30 days after the operation. The use of sugammadex had no effect on the net hospital charge and total charge after RALP, although we revealed that charge for anesthesia was increased.

Oh et al. similarly showed that sugammadex reduced hospital LOS; however, they found that it reduced net charge and 30-day unplanned readmission in patients who underwent major abdominal surgery [6]. In contrast, we found no reduction in unplanned readmission, even after considering the residual distance from the hospital (less than $50 \mathrm{~km}$ ). This difference between the studies may be related to the different types of surgery between the studies. Oh et al. included study subjects who underwent major abdominal surgery with a procedure time $>2 \mathrm{~h}$ and estimated blood loss $>500 \mathrm{~mL}$. On the other hand, RALP is a prolonged surgery, lasting 3.8 $\mathrm{h}$, and involving the steep Trendelenburg position. However, most of the elective surgeries were performed by 


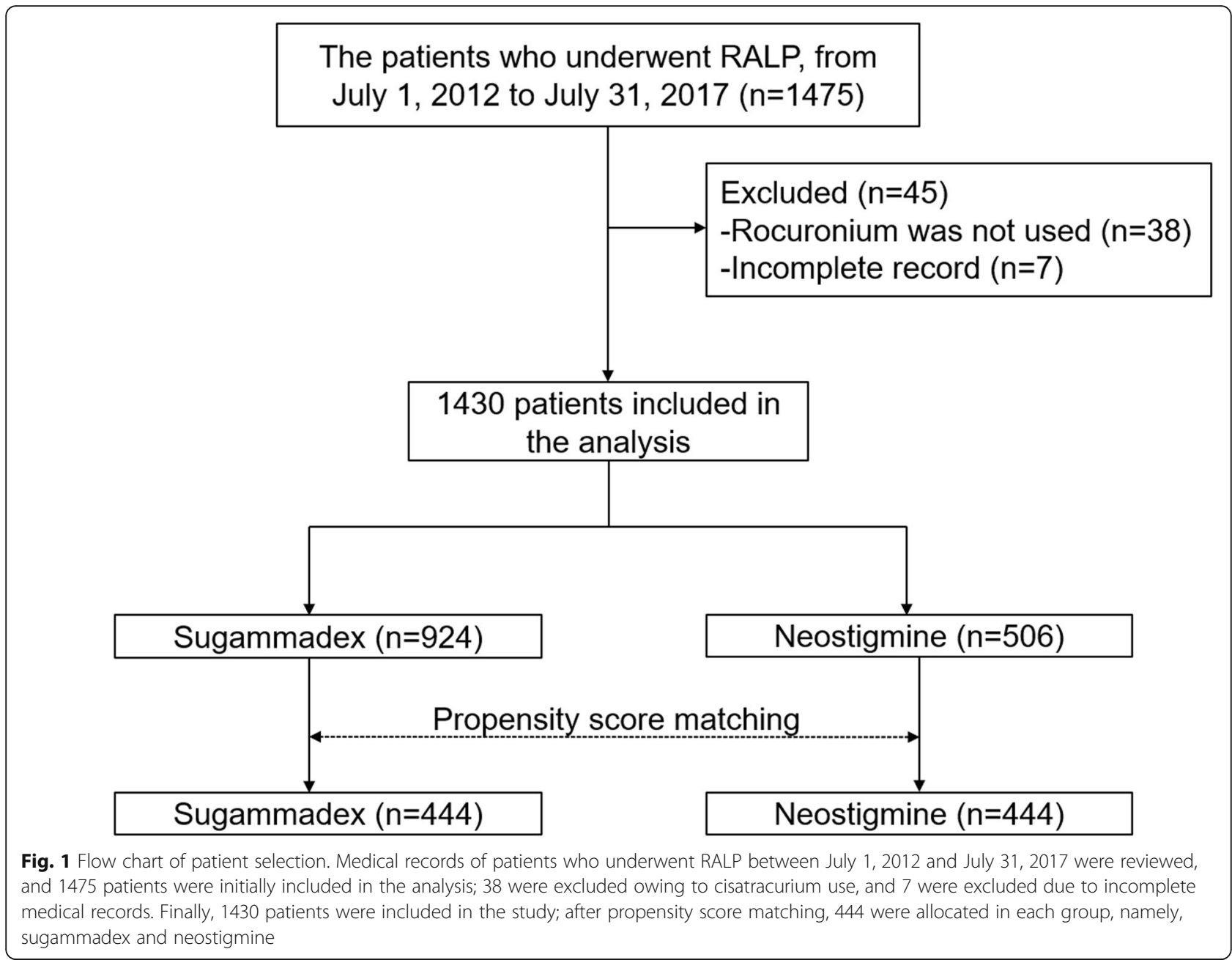

skillful expert surgeons, with a mean blood loss of only $166.1 \mathrm{~mL}$, and the readmission rate was only $1.3 \%$ in our hospital.

We could not find appropriate and reliable records of pulmonary complications in patients who underwent RALP. Postoperative chest imaging or laboratory or device-based monitoring of oxygenation was not routinely performed after this surgery. Thus, we could not retrospectively assess the incidence of lung complications, such as atelectasis, bronchitis, pulmonary collapse due to mucus plugging of the airways, or pneumonia, related to surgery. Alternatively, we reviewed post-anesthetic recovery records, but there were no critical respiratory events by predefined definition [12] except the two patients who had cardiovascular events with known coronary artery disease. Therefore, we used postoperative recovery room LOS, hospital LOS, readmission rate, and net charges as surrogates [13-15].

For laparoscopic or robot-assisted surgery, the duration of the operation, the patient's age, smoking status, and residual NMB, have been reported to be related to a prolonged hospital stay [16]. The prevalence of residual NMB in the post-anesthetic recovery room (TOF < 0.9 ) was reported to be about $64 \%$ in several multicenter studies. Residual NMB makes patients vulnerable to hypoxic damage and can cause aspiration due to the weakness of the upper airway muscle following increased recovery time and postoperative hospital stay [17]. This is consistent with our result since sugammadex reduced the LOS in the post-anesthetic recovery room and the hospital. According to a study by Murphy and colleagues, residual NMB caused a 150-min prolongation of mechanical ventilation duration in the intensive care unit in patients who had undergone cardiac surgery $[6,18,19]$.

Sugammadex increased the anesthesia charge; however, it did not increase the postoperative net and total charges related to RALP. Although the use of sugammadex reduced the hospital LOS, it had no effect on the net hospital charge in our study. This result might be due to several reasons. 
Table 1 Characteristics and outcomes of patients who underwent robot-assisted laparoscopic prostatectomy

\begin{tabular}{|c|c|}
\hline Variable & All patients $(N=1430)$ \\
\hline Age, year & $66.3(7.2)$ \\
\hline Body mass index, $\mathrm{kg} \mathrm{m}^{-2}$ & $24.7(5.1)$ \\
\hline \multicolumn{2}{|l|}{ ASA physical status } \\
\hline 1 & 486 (34\%) \\
\hline 2 & $843(59 \%)$ \\
\hline$\geq 3$ & $101(7.1 \%)$ \\
\hline Charlson Comorbidity Index score & $4.73(1.22)$ \\
\hline 2 & $21(1.5 \%)$ \\
\hline 3 & $165(11.5 \%)$ \\
\hline 4 & $456(31.9 \%)$ \\
\hline 5 & $479(33.5 \%)$ \\
\hline 6 & $202(14.1 \%)$ \\
\hline$\geq 7$ & $107(7.7 \%)$ \\
\hline \multicolumn{2}{|l|}{ Anesthesia related factors } \\
\hline NMB reversal agents (sugammadex vs. neostigmine) & $924(64.6 \%)$ vs. 506 (35.4\%) \\
\hline Intraoperative remifentanil dose, per $100 \mathrm{mcg}$ & $9.7(4.6)$ \\
\hline Intraoperative rocuronium dose, per 10 mg & $8.1(2.2)$ \\
\hline Intraoperative estimated blood loss, mL & $166.1(138.2)$ \\
\hline Duration of anesthesia, $\mathrm{h}$ & $4.0(0.8)$ \\
\hline \multicolumn{2}{|l|}{ Outcomes } \\
\hline Length of hospital stay, days & $7.8(2.1)$ \\
\hline Readmission within 30 days & $29(2 \%)$ \\
\hline Unplanned readmission within 30 days due to surgical problem & $18(1.3 \%)$ \\
\hline \multicolumn{2}{|l|}{ Cause of unplanned readmission within 30 days due to surgical problems } \\
\hline Voiding difficulty & 10/18 (56\%) \\
\hline Intrapelvic fluid collection & $4 / 18(22 \%)$ \\
\hline lleus & $2 / 18(11 \%)$ \\
\hline \multicolumn{2}{|l|}{ Charge } \\
\hline Total charges for postoperative hospitalization, United States dollars & $11,034(1942)$ \\
\hline Net charges for postoperative hospitalization, United States dollars & $2918(1271)$ \\
\hline Charges for anesthesia, United States dollars & $344(78)$ \\
\hline
\end{tabular}

ASA American Society of Anesthesiologists, NMB Neuromuscular blockade

Presented as $\mathrm{n}(\%)$ or mean (standard deviation) or median (interquartile range)

First, the net charge was defined at the total charge of healthcare services provided during admission except for the charge of the operation and anesthesia; thus, the staff expenses per time were excluded. There was a marked difference in concept between charge and cost. We analyzed the charge (i.e., the amount paid by the patient and government for our hospital's medical services and medical products) because we could not obtain sufficient data to calculate cost retrospectively. Several review articles have also found that the use of sugammadex had no benefits on overall hospital costs [4, 20, 21]. In studies that claimed the cost-effectiveness of sugammadex, the "saved time" of anesthetic recovery was measured and multiplied with "the estimated value of the time of each staff member." In this manner, they proved decreased time spent in the recovery room. However, the national healthcare system and the staff working patterns differ between studies, and thus, we should interpret the results considering certain conditions.

Second, RALP is a stereotypical surgery that would make no economic difference among patients. Patients who underwent RALP had a shorter recovery time and fewer complications compared to those who underwent retropubic radical prostatectomy [22]. In our study, the 
Table 2 Comparison between sugammadex and neostigmine groups before and after propensity score-matching. Presented as $\mathrm{n}$ (\%) or mean (SD)

\begin{tabular}{|c|c|c|c|c|c|c|}
\hline & \multicolumn{2}{|c|}{$\begin{array}{l}\text { Before propensity score-matching } \\
(n=1430)\end{array}$} & \multirow[t]{2}{*}{ ASD } & \multicolumn{2}{|c|}{$\begin{array}{l}\text { After propensity score-matching } \\
(n=888)\end{array}$} & \multirow[t]{2}{*}{ ASL } \\
\hline & $\begin{array}{l}\text { Sugammadex } \\
(n=924)\end{array}$ & $\begin{array}{l}\text { Neostigmine } \\
(n=506)\end{array}$ & & $\begin{array}{l}\text { Sugammadex } \\
(n=444)\end{array}$ & $\begin{array}{l}\text { Neostigmine } \\
(n=444)\end{array}$ & \\
\hline Age, year $(\geq 65)$ & $579(62.7)$ & $310(61.3)$ & 0.03 & $270(60.8)$ & $261(58.8)$ & 0.04 \\
\hline Body mass index, $\mathrm{kg} \mathrm{m}^{-2}$ & $24.5(2.7)$ & $25.1(7.7)$ & 0.20 & $24.7(2.7)$ & $24.9(6.2)$ & 0.08 \\
\hline Charlson Comorbidity Index score & $4.7(1.2)$ & $4.8(1.2)$ & 0.07 & $4.8(1.3)$ & $4.8(1.2)$ & 0.06 \\
\hline \multicolumn{7}{|l|}{ ASA physical status } \\
\hline 1 & $302(32.6)$ & $184(36.4)$ & & $159(35.8)$ & $151(34.0)$ & \\
\hline 2 & $554(60.0)$ & $289(57.1)$ & 0.05 & 255(57.4) & $261(58.8)$ & 0.03 \\
\hline$\geq 3$ & $68(7.4)$ & $33(6.5)$ & 0.03 & $30(6.8)$ & $32(7.2)$ & 0.02 \\
\hline \multicolumn{7}{|l|}{ Intraoperative rocuronium dose, mg } \\
\hline$\geq 50$, and $<100$ & $742(80.2)$ & $420(82.8)$ & 0.02 & $381(85.8)$ & $383(86.3)$ & 0.01 \\
\hline$\geq 100$ & $176(19.0)$ & $78(15.4)$ & 0.11 & $32(7.2)$ & $39(8.8)$ & 0.05 \\
\hline Intraoperative remifentanil dose, per $100 \mathrm{mcg}(\geq 10)$ & $76(8.2)$ & $112(22.1)$ & 0.52 & $62(14.0)$ & $59(13.3)$ & 0.02 \\
\hline Total intravenous anesthesia & 68(13.4) & $38(4.1)$ & 0.47 & $35(7.9)$ & $29(6.5)$ & 0.07 \\
\hline Duration of anesthesia, $\mathrm{h}$ & $3.9(0.7)$ & $4.2(0.8)$ & 0.34 & $4.1(0.8)$ & $4.1(0.7)$ & 0.07 \\
\hline Estimated blood loss, L & $0.15(0.1)$ & $0.19(0.1)$ & 0.25 & $0.2(0.2)$ & $0.2(0.1)$ & 0.08 \\
\hline \multicolumn{7}{|l|}{ Distance, $\mathrm{km}^{\mathrm{a}}$} \\
\hline$\geq 40$, and $<180$ & $44(8.7)$ & 191(20.7) & 0.29 & $44(9.9)$ & $40(9.0)$ & 0.02 \\
\hline $180 \geq$ & 20(2.0) & 201(21.8) & 0.43 & $20(4.5)$ & $28(6.3)$ & 0.0 \\
\hline Operation by skilled surgeon ${ }^{\text {b }}$ & $810(87.6)$ & 407 (80.3) & 0.21 & $367(82.7)$ & 382 (860.) & 0.1 \\
\hline
\end{tabular}

ASA American Society of Anesthesiologists, ASD absolute value of standardized mean difference

Presented as $\mathrm{n}(\%)$ or mean (standard deviation)

a Distance means the distance between home and the hospital

${ }^{b}$ Surgeons who had done robot-assisted laparoscopic prostatectomy more than 200 cases

average hospital stay was 7.8 days (standard deviation, 2.5 days). Moreover, compared to open retropubic or laparoscopic surgery, RALP is associated with a lower mortality and transfusion rate [7] which would reduce the postoperative hospital stay. There was no significant difference in total charge, including the charge for surgery, between sugammadex use and neostigmine use, even though anesthesia charge in cases where sugammadex was used was higher than those in which neostigmine was used. This indicated that the effect of sugammadex cost on the total charge was limited.

Finally, medical resources in South Korea are quite inexpensive because of the wide national insurance coverage. The major part of the financial burden was the charge for robotic surgery, but this was excluded from our analysis. Therefore, reduced hospital stays had no effects on the net charge. Risk factors for an increased net charge were the total dose of rocuronium used, the

Table 3 Effect of sugammadex on length of stay in the post-anesthesia care unit, post-operative hospital stay and unplanned readmission, as compared to neostigmine, in patients who underwent robot-assisted laparoscopic prostatectomy, based on a propensity score-matched cohort

\begin{tabular}{|c|c|c|c|c|c|c|c|c|c|}
\hline \multirow[b]{2}{*}{ Variable } & \multicolumn{3}{|c|}{$\begin{array}{l}\text { Length of stay in the post-anesthesia care } \\
\text { unit (min) }\end{array}$} & \multicolumn{3}{|c|}{ Hospital LOS after surgery (days) } & \multicolumn{3}{|c|}{ Unplanned readmission within 30 days } \\
\hline & Mean (SD) & $\begin{array}{l}\text { Odds ratio } \\
{[95 \% \mathrm{Cl}]}\end{array}$ & $\begin{array}{l}P \\
\text { value }^{a}\end{array}$ & $\begin{array}{l}\text { Mean } \\
\text { (SD) }\end{array}$ & $\begin{array}{l}\text { Odds ratio } \\
{[95 \% \mathrm{Cl}]}\end{array}$ & $\begin{array}{l}P \\
\text { value }^{b}\end{array}$ & $\mathrm{~N}(\%)$ & $\begin{array}{l}\text { Odds ratio } \\
(95 \% \mathrm{Cl})\end{array}$ & $\begin{array}{ll}P \\
\text { value }^{c}\end{array}$ \\
\hline $\begin{array}{l}\text { Sugammadex vs. } \\
\text { Neostigmine }\end{array}$ & $\begin{array}{l}36.7(8.4) \text { vs. } 40.2 \\
(13.0)\end{array}$ & $0.92[0.90,0.94]$ & $\begin{array}{l}< \\
0.001\end{array}$ & $\begin{array}{l}7.7(2.5) \\
\text { vs. 8.2 } \\
(2.0)\end{array}$ & $0.94[0.89,0.98]$ & 0.008 & $\begin{array}{l}9(2.0 \%) \text { vs. } 5 \\
(1.1 \%)\end{array}$ & $1.82[0.60,5.46]$ & 0.288 \\
\hline
\end{tabular}

\footnotetext{
a,b Length of stay in the post-anesthesia care unit, hospital length of stay after surgery: a generalized linear model assuming Poisson distribution and a log link function were used. $P<0.05$ was considered as statistically significant
}

'30-Day unplanned readmission: logistic regression analysis was used. $P<0.05$ was considered as statistically significant 
Table 4 Effect of sugammadex on the charge for anesthesia, net charge, and total charge, as compared to neostigmine, in patients who underwent robot-assisted laparoscopic prostatectomy, based on a propensity score-matched cohort

\begin{tabular}{|c|c|c|c|c|c|c|c|c|c|}
\hline \multirow[t]{2}{*}{ Variable } & \multicolumn{3}{|c|}{ Charge for anesthesia (USD) } & \multicolumn{3}{|c|}{ Postoperative net charge ${ }^{\mathrm{a}}($ USD) } & \multicolumn{3}{|c|}{ Postoperative total charge(USD) } \\
\hline & Median (IQR) & $\begin{array}{l}\text { Odds ratio } \\
{[95 \% \mathrm{CI}]}\end{array}$ & $\begin{array}{l}P \\
\text { value }^{b}\end{array}$ & Median (IQR) & $\begin{array}{l}\text { Odds ratio } \\
(95 \% \mathrm{Cl})\end{array}$ & $\begin{array}{l}P \\
\text { value }^{c}\end{array}$ & Median (IQR) & $\begin{array}{l}\text { Odds ratio } \\
(95 \% \mathrm{Cl})\end{array}$ & $\begin{array}{l}P \\
\text { value }^{d}\end{array}$ \\
\hline $\begin{array}{l}\text { Sugammadex } \\
\text { vs. } \\
\text { Neostigmine }\end{array}$ & $\begin{array}{l}343(307-393) \\
\text { vs. } 326(291- \\
361)\end{array}$ & $1.07[1.04,1.10]$ & $<0.001$ & $\begin{array}{l}2589(2246-3347) \\
\text { vs. } 2456(2180- \\
3179)\end{array}$ & $1.04[1.00,1.09]$ & 0.061 & $\begin{array}{l}10,875(10055-11 \\
843) \text { vs. } 11,588(9659- \\
12,522)\end{array}$ & $0.98[0.96,1.00]$ & 0.100 \\
\hline
\end{tabular}

$I Q R$ interquartile range

a Net hospital charge: total hospital charge - charges for surgery and anaesthesia

$b, c, d$ Generalised linear model assuming gamma distribution and log link function was used, and $P<0.05$ was considered as statistically significant

duration of surgery or anesthesia, and the Charlson Comorbidity Index. It is thought that a delicate operation would take a marked amount of time and would demand much more postoperative care.

There were several limitations to our study. First of all, this was a single-center study, and cannot be fully representative. Second, this could be considered a historical cohort retrospective study, as it included data from 2012 to 2017. Sugammadex was introduced to our hospital in 2013, and its use started from 2014. After the introduction of sugammadex, anesthesiologists were able to select $\mathrm{NMB}$ reversal agents based on their preferences; after it was made available in our hospital, almost all anesthesiologists appeared to have a preference for sugammadex over neostigmine. However, when we performed the analysis to find factors including the time of surgery, that influences clinical outcomes such as LOS in the PACU, hospital, charges, unplanned re-admission rates, the timing of the surgery did not impact the results. This may be attributed to the fact that staff at our hospital had started RALP surgery long before the study period, and had already developed a protocol for this surgery and anesthesia; the process was therefore well established before initiation of the study. Therefore, we did not consider the time of surgery in the propensity score matching model. Third, we used the intraoperative rocuronium dose but did not include the degree of NMB (moderate or deep) in the analysis. We usually monitor NMB using a nerve stimulator (EZstim II, ES400, Life-Tech, Camarillo, CA, USA), TOF scan (idmed, Drager, Telford, PA, USA), or NMT module (Nihon Kohden, Shinjuku, Japan) depending on the anesthesiologist's preference. However, this was not recorded in the medical records. The volume of sugammadex required differs according to the degree of NMB (at most $16 \mathrm{mg} \mathrm{kg}^{-1}$ ), which affects cost-effectiveness [20]. Lastly, in our study, the intraoperative dose of rocuronium was higher in the sugammadex group than in the neostigmine group. Apparently, anesthesiologists use rocuronium freely when they plan to use sugammadex, or they prefer sugammadex over neostigmine when they use a higher dose of rocuronium; the benefits of deeper block of NMJ are controversial. In a metaanalysis of ten studies, there was a reduction in intraabdominal pressure (IAP) in three studies, and in the pain score after $24 \mathrm{~h}$ of surgery in two studies; however, in other two studies there were no differences in terms of the post-operative pain score and LOS among deep or moderate NMB groups [23]. In contrast, higher doses of rocuronium may be related to residual curarization and prolongation of stay in the PACU. We performed an analysis using a PSM model matched with multiple factors including the rocuronium dose, as described in the methods section; as a result, the stay in hospital and the PACU was shortened in the group receiving sugammadex compared to that receiving neostigmine. This did not lead to an increase in critical respiratory events in the recovery room.

\section{Conclusion}

In this study, we showed that the length of hospital stay, as well as the length of the postoperative stay in the PACU, after RALP was shorter in patients in whom sugammadex, rather than neostigmine, was used for reversal of NMB. The net charge and unplanned readmission rate within 30 days after surgery showed no benefit in the sugammadex group as compared to the neostigmine group. Further studies should investigate the economic advantage or postoperative complications (acute and long term) of using sugammadex according to the type of surgery. If its economic effectiveness is clarified, sugammadex can be used routinely, with rare complications.

\section{Abbreviations \\ ASA: American Society of Anesthesiologists; LOS: Length of stay: NMB: Neuromuscular blockade; RALP: Robot-assisted laparoscopic prostatectomy; TOF: Train-of-four}

\section{Acknowledgments}

The authors thank the Medical Informatics team at Seoul National University Bundang Hospital for their dedicated work. We are particularly grateful to all the professors of the Department of Urology. 


\section{Authors' contributions}

BHM: The author designed study, drafted paper, helped data acquisition, and data analysis, and approved the final paper.; TKO: The author designed study, drafted paper, helped data acquisition, and data analysis, and approved the final paper; IAS: The author designed study, drafted paper, helped data acquisition, and data analysis, and approved the final paper.; YTJ: The author helped data acquisition, data interpretation, and critical revisions of paper, and approved the final paper. The authors read and approved the final manuscript.

\section{Funding}

None.

\section{Availability of data and materials}

The dataset used and analyzed during the current study is available from the corresponding author on reasonable request.

\section{Ethics approval and consent to participate}

This study was approved by the Institutional Review Board (B-1901/514-115) of Seoul National University Bundang Hospital, which waived the requirement for obtaining informed patient consent.

\section{Consent for publication}

Not applicable.

\section{Competing interests}

The authors declare that they have no competing interests.

\section{Author details}

'Department of Anesthesiology and Pain Medicine, Seoul National University Bundang Hospital, Gumi-ro 173 Beon-gil, Bundang-gu, Seongnam-si, Gyeonggi-do, Republic of Korea. ${ }^{2}$ Interdepartment of Critical Care Medicine, Seoul National University Bundang Hospital, 166, Gumi-ro 173 Beon-gil, Bundang-gu, Seongnam-si, Gyeonggi-do 463-707, Republic of Korea. ${ }^{3}$ Department of Anaesthesiology and Pain Medicine, Seoul National University, 103 Daehak-ro, Jongno-gu, Seoul, Republic of Korea.

Received: 24 November 2019 Accepted: 9 July 2020

Published online: 21 July 2020

\section{References}

1. Shields M, Giovannelli M, Mirakhur RK, Moppett I, Adams J, Hermens Y. Org 25969 (sugammadex), a selective relaxant binding agent for antagonism of prolonged rocuronium-induced neuromuscular block. Br J Anaesth. 2006; 96(1):36-43.

2. Ledowski T, Hillyard S, Kozman A, Johnston F, Gillies E, Greenaway M, Kyle BC. Unrestricted access to sugammadex: impact on neuromuscular blocking agent choice, reversal practice and associated healthcare costs. Anaesth Intensive Care. 2012;40(2):340-3.

3. Carron M, Zarantonello F, Lazzarotto N, Tellaroli P, Ori C. Role of sugammadex in accelerating postoperative discharge: a meta-analysis. J Clin Anesth. 2017:39:38-44.

4. Schaller SJ, Fink H. Sugammadex as a reversal agent for neuromuscular block: an evidence-based review. Core Evidence. 2013;8:57-67.

5. Carron M, Baratto F, Zarantonello F, Ori C. Sugammadex for reversal of neuromuscular blockade: a retrospective analysis of clinical outcomes and cost-effectiveness in a single center. ClinicoEcon Outcomes Res. 2016;8:43.

6. Oh TK, Oh A-Y, Ryu J-H, Koo B-W, Song I-A, Nam SW, Jee H-J. Retrospective analysis of 30-day unplanned readmission after major abdominal surgery with reversal by sugammadex or neostigmine. Br J Anaesth. 2019;122(3): 370-8.

7. Yu HY, Hevelone ND, Lipsitz SR, Kowalczyk KJ, Hu JC. Use, costs and comparative effectiveness of robotic assisted, laparoscopic and open urological surgery. J Urol. 2012;187(4):1392-8.

8. Kilic OF, Börgers A, Köhne W, Musch M, Kröpfl D, Groeben H. Effects of steep Trendelenburg position for robotic-assisted prostatectomies on intraand extrathoracic airways in patients with or without chronic obstructive pulmonary disease. Br J Anaesthesia. 2015;114(1):70-6.

9. Maerz D, Beck L, Sim A, Gainsburg D. Complications of robotic-assisted laparoscopic surgery distant from the surgical site. Bri J Anaesthesia. 2017; 118(4):492-503.
10. Lim B. Korean medicine coverage in the National Health Insurance in Korea: present situation and critical issues. Integr Med Res. 2013;2(3):81-8.

11. Bhandari A, Intire LM, Kaul SA, Hemal AK, Peabody JO, Menon M. Perioperative complications of robotic radical prostatectomy after the learning curve. J Urol. 2005;174(3):915-8.

12. Murphy GS, Szokol JW, Marymont JH, Greenberg SB, Avram MJ, Vender JS. Residual neuromuscular blockade and critical respiratory events in the postanesthesia care unit. Anesth Analg. 2008;107(1):130-7.

13. Regenbogen SE, Cain-Nielsen AH, Norton EC, Chen LM, Birkmeyer JD, Skinner JS. Costs and consequences of early hospital discharge after major inpatient surgery in older adults. JAMA Surg. 2017;152(5):-e170123.

14. Krell RW, Girotti ME, Dimick JB. Extended length of stay after surgery: complications, inefficient practice, or sick patients? JAMA Surg. 2014;149(8): 815-20

15. Khan NA, Quan H, Bugar JM, Lemaire JB, Brant R, Ghali WA. Association of postoperative complications with hospital costs and length of stay in a tertiary care center. J Gen Intern Med. 2006;21(2):177-80.

16. Chong JU, Lee JH, Yoon YC, Kwon KH, Cho JY, Kim SJ, Kim JK, Kim SH, Choi SB, Kim KS. Influencing factors on postoperative hospital stay after laparoscopic cholecystectomy. Korean J Hepatobiliary Pancreat Surg. 2016; 20(1):12-6.

17. Murphy GS, Brull SJ. Residual neuromuscular block: lessons unlearned. Part I: definitions, incidence, and adverse physiologic effects of residual neuromuscular block. Anesth Analg. 2010;111(1):120-8.

18. Murphy GS, Szokol JW, Marymont JH, Avram MJ, Vender JS, Rosengart TK. Impact of shorter-acting neuromuscular blocking agents on fast-track recovery of the cardiac surgical patient. Anesthesiology. 2002;96(3):600-6.

19. Abad-Gurumeta A, Ripollés-Melchor J, Casans-Francés R, Espinosa A, Martínez-Hurtado E, Fernández-Pérez C, Ramírez J, López-Timoneda F, Calvo-Vecino J, Group EAR. A systematic review of sugammadex vs neostigmine for reversal of neuromuscular blockade. Anaesthesia. 2015; 70(12):1441-52.

20. Paton F, Paulden M, Chambers D, Heirs M, Duffy S, Hunter JM, Sculpher M, Woolacott N. Sugammadex compared with neostigmine/glycopyrrolate for routine reversal of neuromuscular block: a systematic review and economic evaluation. Br J Anaesth. 2010;105(5):558-67.

21. Paton F, Heirs M, Woolacott N, Chambers D, Duffy S, Sculpher M, Paulden M, Hunter JM. Sugammadex for reversal of neuromuscular block after rapid sequence intubation: a systematic review and economic assessmentt. Br J Anaesthesia. 2010;105(5):568-75.

22. Novara G, Ficarra V, Rosen RC, Artibani W, Costello A, Eastham JA, Graefen M, Guazzoni G, Shariat SF, Stolzenburg J-U. Systematic review and metaanalysis of perioperative outcomes and complications after robot-assisted radical prostatectomy. Eur Urol. 2012;62(3):431-52.

23. Bruintjes M, Van Helden E, Braat A, Dahan A, Scheffer G, Van Laarhoven C, Warle M: Deep neuromuscular block to optimize surgical space conditions during laparoscopic surgery: a systematic review and meta-analysis. BJA: British Journal of Anaesthesia. 2017;118(6):834-42.

\section{Publisher's Note}

Springer Nature remains neutral with regard to jurisdictional claims in published maps and institutional affiliations.

Ready to submit your research? Choose BMC and benefit from:

- fast, convenient online submission

- thorough peer review by experienced researchers in your field

- rapid publication on acceptance

- support for research data, including large and complex data types

- gold Open Access which fosters wider collaboration and increased citations

- maximum visibility for your research: over $100 \mathrm{M}$ website views per year

At $\mathrm{BMC}$, research is always in progress.

Learn more biomedcentral.com/submissions 